\title{
CHILDREN, UNHAPPINESS AND FAMILY FINANCES: EVIDENCE FROM ONE MILLION EUROPEANS
}

\author{
David G. Blanchflower \\ Andrew E. Clark \\ Working Paper 25597 \\ http://www.nber.org/papers/w25597 \\ NATIONAL BUREAU OF ECONOMIC RESEARCH \\ 1050 Massachusetts Avenue \\ Cambridge, MA 02138 \\ February 2019
}

The views expressed herein are those of the authors and do not necessarily reflect the views of the National Bureau of Economic Research.

NBER working papers are circulated for discussion and comment purposes. They have not been peer-reviewed or been subject to the review by the NBER Board of Directors that accompanies official NBER publications.

(C) 2019 by David G. Blanchflower and Andrew E. Clark. All rights reserved. Short sections of text, not to exceed two paragraphs, may be quoted without explicit permission provided that full credit, including $\odot$ notice, is given to the source. 
Children, Unhappiness and Family Finances: Evidence from One Million Europeans

David G. Blanchflower and Andrew E. Clark

NBER Working Paper No. 25597

February 2019

JEL No. D14,I31,J13

\begin{abstract}
$\underline{\text { ABSTRACT }}$
The common finding of a zero or negative correlation between the presence of children and parental well-being continues to generate research interest. We here consider over one million observations on Europeans from ten years of Eurobarometer surveys, and in the first instance replicate this negative finding, both in the overall data and then for most different marital statuses. Children are expensive, and controlling for financial difficulties turns almost all of our estimated child coefficients positive. We argue that financial difficulties explain the pattern of existing results by parental education and income, and country income and social support. Marital status matters. Kids do not raise happiness for singles, the divorced, separated or widowed. Last, we underline that all children are not the same, with step-children commonly having a more negative correlation than children from the current relationship.
\end{abstract}

David G. Blanchflower

Bruce V. Rauner Professor of Economics

6106 Rockefeller Hall

Dartmouth College

Hanover, NH 03755-3514

and NBER

David.G.Blanchflower@Dartmouth.EDU

Andrew E. Clark

Paris School of Economics

48 Bd Jourdan

75014 Paris France

Andrew.Clark@ens.fr 


\section{Introduction}

The empirical analysis of the relationship between the presence of children and parental subjective well-being has produced a variety of results. While some analyses have found positive correlations, these do not apply to all parents equally, and other work has concluded as to a negative effect of children on parental well-being. As Cetre et al. (2016) note, subjective well-being scores are usually well-behaved, in that they produce estimated coefficients that fit with our predictions; on the contrary, the estimated coefficients on children do not always fit well with our guess that (at least for evolutionary reasons) children should produce well-being.

A number of results from the existing literature are discussed in Online Annex 5 of Clark et al. (2018), available at http://cep.lse.ac.uk/origins/onlinematerial.pdf. These broadly show a divergence of findings in the cross-sectional literature (with negative estimated coefficients in, for example, Deaton and Stone, 2014, Alesina et al., 2004, and Stanca, 2012, but small positive correlations in Aasve et al., 2012, and Cetre et al., 2016). Fixed-effect analysis tends to produce more positive findings: see Clark et al. (2008), Stutzer and Frey (2006) and Figure 5.6 in Clark et al. (2018). Kahneman, Krueger, Schkade, Schwarz, and Stone, (2004) found that child care was only slightly more enjoyable than housework or commuting to work.

While economists in general tend to prefer fixed-effects to cross-section analysis, the former mechanically tends to focus on young children (due to its requirement that the parent be observed both before and after the childbirth), and most existing panels are not long enough for us to say much about the relationship between children and parental well-being in panel analysis when the former are in their teens or older. ${ }^{1}$ The effect of children in general may well be different from that of young children. The lags and leads analysis in Clark et al. (2018) suggest that life satisfaction rises at birth but then turns negative when the child is aged two. However, the slope in life satisfaction as the child ages then looks positive (at least for mothers) and it is intriguing to speculate on what its shape might be as the children age. ${ }^{2}$ Cross-sectional analysis, on the contrary, allows us to consider children of all ages.

As well as calculating an average effect of all children, sometimes distinguishing by (young) child age, it is of interest to ask which parents do better (or worse) as children come around. Existing work suggests that the relationship between children and parental well-being is more likely to be positive in richer countries, with one interpretation being that children are more likely to be chosen there (see McLanahan and Adams, 1987).

Children are also more likely to be associated with higher subjective well-being for older parents: the positive effects of children in Deaton and Stone, 2014, are found for parents who are aged 3446, and in Margolis and Myrskylä (2011) the estimated coefficients on children for those aged under 30, 30-39, and over 40 are respectively negative, zero and positive (see also Stanca, 2012, for evidence from the World Values Survey).

\footnotetext{
${ }^{1}$ A similar point applies to the instrumental-variable analysis in Costa-Font et al. (2018), which relies on a 2007 parental-leave reform in Germany. The children here are all fairly young.

${ }^{2}$ The length of the SOEP panel does allow Myrskylä and Margolis (2014) to consider the relationship between parental life satisfaction and a small number of children up to teen ages. They find a positive life-satisfaction effect around childbirth, but no significant relationship thereafter.
} 
With respect to socioeconomic resources, which will be one of our main areas of interest in the current paper, Margolis and Myrskylä (2011) divide their World Values Survey respondents up into three income groups, according to their self-reported income decile (Low = deciles 1-4, Middle $=$ deciles 5-6 and High $=$ deciles 7-10). Although the differences are only small, for the under-40's the relationship between children and life satisfaction is more negative for the lowincome group (there is no clear difference in this respect between the middle- and high-income groups). In the analysis of BHPS and SOEP data in Myrskylä and Margolis (2014), the subjective well-being trajectory of the higher-educated is above that of less-educated parents (see their Figure 4), although the differences do not appear to be significant.

Glass, Simon, and Andersson (2016) compared the happiness levels of couples with and without children from 22 countries using data from the 2007 and 2008 waves of the International Social Survey Programme and the 2006 and 2008 European Social Surveys. They found that although children lowered happiness in some countries, parents in other nations experienced a happiness surplus. For example, compared with childless couples, parents with children in Norway and Hungary tend to be happier. However, parents in Australia and Great Britain were less happy than their childless counterparts. The country with the largest happiness deficit related to having children was the United States. The authors argue that the parenthood gap is explained by differences in State-provided family support, and hypothesize that the broader policy context helps explain why adults living with children report lower happiness than those who do not live with children. They estimate that the parental-status happiness gap will be smaller in countries with more-generous family policies than in countries that provide minimal public assistance to parents.

Herbst and Ifcher (2016) examined the relationship between parental status and happiness using data from the General Social Survey from 1972 through 2008 and the DDB Needham Lifestyle Survey from 1985-2005. They found that parents' relative happiness has been increasing over time, a finding that is driven by the absolute decline in non-parents' happiness. The authors also find that the parental happiness gap depends on the time-period and age-group analyzed. There is no evidence of a parental gap well-being for those aged 45 and under. In what follows we will also find marked differences in well-being and children for those in their childbearing years under the age of forty-five and those who are older.

One of the major findings of our work here is that family finances play a key role in our analysis of Eurobarometer data: once we control for the difficulty in paying bills the negative impact of children on life satisfaction disappears and becomes positive. We also find evidence that children under the age of ten raise happiness but that this is less the case for children aged 10-14. There are also differences by age of respondent.

We in addition underline that the correlation between parental well-being and the presence of children at older ages depends critically on whether the children are your own or not. It is wellknown that separation and divorce are associated with lower well-being, although work does find adaptation over time to these phenomena. Our findings here show, however, that separation and divorce may continue to play a role in the longer run via the presence of step-children. 
The remainder of the paper is organized as follows. Section 2 describes our data from the Eurobarometer. Section 3 then presents our main regression results, estimating the relationship between children and life satisfaction for 15 marital-status/children groups, and then demonstrating the importance of family finances in explaining the patter of results. Last, Section 4 concludes.

\section{Data}

We will here analyse European data to set out the relationship between children and well-being. But as background, and to illustrate the common finding that children lower well-being, we first look at data from the US General Social Survey from 1972-2016, as used in Blanchflower and Oswald (2004). The happiness question in the GSS is 'taken all together, how would you say things are these days - would you say that you are very happy (=3), pretty happy (=2), or not too happy (=1)?' (GSS question 157). The numbers in parentheses refer to how we coded the variable. We regressed happiness on age and its square, gender, a Black ethnicity dummy, years of education, seven labor-force status dummies, four marital-status dummies, a time trend and a dummy variable for there being any children in the household. The coefficient on the children present variable was negative and statistically significant: in a standard US happiness equation children lower happiness. ${ }^{3}$

Our main contribution here is based on large-scale European cross-section data from multiple repeated cross-section Eurobarometer surveys in the form of an unbalanced panel of countries. The Standard Eurobarometer series has been running for 45 years now, having been established in 1974. There are several surveys a year, consisting of interviews with around 1000 respondents in each participating country. ${ }^{4}$ Not all of the surveys include questions on life satisfaction but an increasing proportion over time do. The Eurobarometer surveys information on respondent's life satisfaction as reported in response to the question "On the whole, are you very satisfied, fairly satisfied, not very satisfied or not at all satisfied with the life you lead?". The possible responses were Very satisfied $(=4)$, Fairly satisfied $(=3)$, Not very satisfied $(=2)$ and Not at all satisfied $(=1)$, with the figure in parentheses showing how we code the variable in our empirical analysis.

We have merged together life satisfaction data from 35 Eurobarometer surveys over the ten-year from 2009-2018..$^{5}$ Prior to 2009 the Eurobarometer surveys only recorded marital status and did not provide information on the presence of children. These surveys produce a total of over one million observations across all twenty-eight EU countries plus Albania, Iceland, Macedonia, Montenegro, Serbia, Turkish Cyprus and Turkey in the post-recession period. The data files include, in addition to the above four-step life-satisfaction variable a number of standard variables

\footnotetext{
${ }^{3}$ The estimated equation had 57,244 observations and, with all the above controls, the coefficient on the children present variable was -.0410 with a t-statistic of 5.63 and an adjusted $\mathrm{R}^{2}$ of .0811 .

${ }^{4}$ This standard series is augmented by Special and Flash Eurobarometers on specific issues.

${ }^{5}$ These are the Eurobarometer surveys we use - 2009=\#71.1; \#71.3; 2010=\#73.4; \#74.2; 2011=\#75.3; \#75.4; \#76.3; $2012=\# 77.4 ; \# 78.1 ; 2013=\# 79.3 ; \# 79.4 ; \# 80.1 ; \# 80.2 ; 2014=\# 81.1 ; \# 81.4 ; \# 81.5 ; \# 82.3 ; \# 82.4 ; 2015=\# 83.1 ; \# 83.2$; $\# 83.3 ; \# 83.4 ; \# 84.2 ; \# 84.3 ; \# 84.4 ; 2016=\# 85.2 ; \# 86.1 ; \# 86.2 ; \# 86.3 ; 2017=\# 87.1 ; \# 87.3 ; \# 88.3 ; \# 88.4$ and $2018=\# 89.1$ and $\# 89.3$.
} 
that appear in life-satisfaction equations, including age and its square, gender, marital status, schooling and labor-force status (Blanchflower and Oswald, 2004, 2008 and 2018).

There are 1,046,785 observations on life satisfaction in our pooled data file across the ten years 2009-2018. Over these years, on the one-to-four scale, mean life satisfaction is 2.93 with a standard deviation of .80. Over time, mean life satisfaction rose from 2.86 in 2009 in the EU countries to 3.01 in 2018. Table 1 reports the average life-satisfaction scores by country for 2009, 2015 and 2018, for the countries which appear in all three data waves. ${ }^{6}$ We can see that the 2018 values are higher than those in 2009 for every country except Belgium, Cyprus, Croatia, Luxembourg and Sweden (where the drop is -0.07 of a point or less), showing the broad recovery in well-being following the start of the financial crisis. In contrast to the 2018 World Happiness Report, which used the Cantril ladder, we do not conclude that Finland has the highest well-being level: it ranks seventh in terms of life satisfaction in our most recent data in 2018 after, in order, Denmark, the Netherlands Sweden, Ireland, the UK and Luxembourg (http://worldhappiness.report/ed/2018/). Greece has the lowest life-satisfaction score, having dropped below Bulgaria in 2012. Italy ranks fifth from last.

Our key right-hand side variables refer to marital status and the presence and number of children living in the household. The Eurobarometer tells us not only about the respondent's current marital situation, but also about the presence of children and, critically, whether these children are from the current relationship. The data are reported separately depending on whether the respondent is single, married, living with a partner, divorced or separated or widowed. We also know the number of children in the household under the age of ten and between ten and fourteen who are living in the household. We are able to analyze the relationship between children and parental well-being separately for older and younger adults (we use age 45 as the split between the two).

The exact question used was as follows along with the numbers of observations for those with and without children. We exclude the 13,166 cases where the respondent did not answer the question, leaving a sample of $1,037,106$.

\section{Q. Which of the following best corresponds to your own current situation?}

\section{MARRIED OR REMARRIED}

No kids Kids

1. Living with children 265,023

2. Living with children of this marriage

281,716

3. Living with the children of a previous marriage

4. Living with the children of this marriage \& of a previous marriage

9,221

SINGLE LIVING WITH A PARTNER

5. Living without children $\quad 70,932$

6. Living with the children of this union

32,733

7. Living with the children of a previous union

6,311

8. Living with the children of this union and of a previous union

5,788

SINGLE

9. Living without children

164,912

10. Living with children

17,728

${ }^{6}$ The full data across all years for all of our countries appears in Appendix Table 1. 
DIVORCED OR SEPARATED

11. Living without children

52,368

12. Living with children

24,923

WIDOWED

13. Living without children

14. Living with children

80,421

17,138

Total

633,656

403,450

Overall $38.9 \%$ of the sample were living with children in the household $(403,450 / 1,037,196)$ and, as might be expected, those aged under 45 are more likely to live with children than those aged 45 and over (48.7\% versus $31.8 \%$ ). We also know that $26.5 \%$ of the sample was living with one or more children under the age of fifteen, with $46.9 \%$ of those under 45 in this category versus $11.4 \%$ for those aged 45 and over, and only $5 \%$ for those aged 60 and over.

Table 2 shows the variety of different marital/children situations that we can identify, together with average life satisfaction on the one-to-four scale. The numbered elements in the top panel of Table 2 show our variety of marital/children statuses. We can then identify individuals who are married or remarried (statuses 1-4), who account for $54.4 \%$ of the sample, those living together (5-8; 11.1\%), single and living alone (9 and 10;17.6\%), divorced or separated (11 and 12; 7.5\%) and widowed (13 and $14 ; 9.4 \%)$. It is in addition possible to identify individuals who have children at home $(2-4 ; 6-8 ; 10,12$ and 14$)$, who represent $38.9 \%$ of the sample. The second panel of Table 2 shows differences in happiness by marital status, and that the divorced, separated and widowed are less satisfied than singles, those living together or the married. Last, we not only know whether these respondents have children, but also how many there are and how old they are. The bottom panels of Table 2 refer to the number of children aged up to 10, and the number of young adolescent children aged 10-14. Life satisfaction rises as the number of young children moves from zero to three and then falls. There is a less marked rise as the number of teenagers rises. We report below that younger children provide more happiness than teenagers.

Average life satisfaction differs by marital status and the presence of children. The happiest group is singles living with a partner without children (with a life-satisfaction score of 3.02). The divorced and widowed have lower life satisfaction than the single or married, and the least satisfied are the widowed with children (2.60), followed by the divorced or separated with children (2.70). The partnered are slightly more satisfied than the (re)married, who are themselves notably more satisfied than singles. Within both marriage and single, those without children are a little more satisfied with their lives than those with children. This is reflected in the difference in life satisfaction in the middle of Table 2 between those with and without children. Last, with respect to child age, it is clear that younger children are associated with higher levels of life satisfaction than are adolescent children.

While these raw data differences are of interest, they do not necessarily reveal the relationship between life satisfaction and children or marital status, as there are many other potential confounders at work here, such as financial constraints and age. In order to hold these factors constant, we turn to regression analysis to produce ceteris paribus estimates: this is the subject of the next section. 


\section{Children and Unhappiness}

We no turn to determining the impact of children on happiness. Table 3 shows the results of estimating standard OLS life-satisfaction equations estimated first on the overall sample and then separately by age and then by gender. We include a full set of country dummies. Our key control variables here are a dummy for children being present in the household, derived from the marital status variable in Table 2, and a simple set of marital-status dummies (living together, single, divorced/separated, and widowed; the omitted category is married). We also include controls for schooling and labor-force status and year. Life satisfaction rises with schooling and is higher for workers and lowest for the unemployed. The estimated coefficients on the year dummies rise over time.

The regression results show that the presence of children is associated with lower satisfaction, overall, in both age of respondent categories and for men and women, which is the usual result found in the literature, although the effect size is small here. The estimated children coefficient in equation 1 , at -.0276 , is only around $3.5 \%$ of a standard deviation $(=0.80)$. The estimated coefficients on the other control variables are consistent with those in the existing literature, in particular revealing a U-shape between life satisfaction and age (see Clark et al., 1996, and Blanchflower and Oswald, 2008, 2018), which here is estimated in column 1 to minimize at age fifty-one. We also find markedly lower levels life satisfaction for the divorced, separated and widowed. The pattern of the estimated coefficients on the country variables (not shown here for space reasons) is also consistent with that in earlier work, being higher in the Nordic countries and lowest in Greece and low in a number of East-European countries.

Table 4 moves on from the simple children and marital-status variables above, replacing them by the combined fifteen marital status and children variables that were presented in Table 2. The happiest group in the first column are the married with no children (the excluded category). Every other group has significantly lower life satisfaction, controlling for the variables listed above. Singles living alone with children and the widowed and divorced/separated with or without children are especially unhappy. Regarding the married, it is notable that children from previous marriages seem to lower happiness more than those from the current relationship. That is true even where children from the present marriage are mixed in with those from a previous relationship. Those living together with or without children are equally happy.

In the case of the younger age group, the happiest are now those who are married with children, who have significantly higher levels of satisfaction than the married without children. Once again singles living with children, and those who are divorced, separated or widowed, with or without children, have significantly lower happiness levels. The older cohort is broadly the same as the overall equation with the married without children having significantly higher satisfaction as compared to any other group.

We now move on to try to understand why the existing literature, as well as our initial analysis reported above, has largely concluded that children do not raise happiness. It turns out that any negative effect of children is frequently reversed once we control for the financial difficulties that the household may have in paying their bills. Children are expensive. Difficulties in paying one's bills is likely highly stressful. 


\section{Difficulties paying the bills and happiness}

Why do children have such different effects according to their parents' marital status? One possibility is that many parents with children struggle to pay their bills for food, accommodation and clothing, toys etc. In this respect, Eurobarometer respondents were asked "During the last twelve months, would you say you had difficulties to pay your bills at the end of the month?", with the response categories almost never/never $(=1)$, occasionally $(=2)$ and most of the time $(=3)$.

Table 5 reports the distribution of financial difficulties by the values of our combined marital status and children variable. The single and the married without children have the least difficulty paying bills. The highest percentage figures for having difficulty paying bills most of the time is found for the single and divorced/separated living with children. In addition, this difficulty broadly rises with the number of children. As such, part of the subjective well-being impact of children might be mediated by financial difficulties. Financial difficulties reduce happiness, as expected, just as income raises happiness (Blanchflower and Oswald, 2004).

The fact that children increase subjective well-being more for parents with higher education could then show that children are associated with a smaller increase in financial distress for the bettereducated. This is indeed what our data show. Below we report the proportion of individuals who say they "never or almost never" have difficulty paying their bills by schooling level and age across all the years $(\mathrm{N}=1,021,138)$. The overall total also includes individuals who didn't answer the question or refused.

\begin{tabular}{llc|cc} 
& \multicolumn{2}{c|}{ Age $<45$} & \multicolumn{2}{c}{ Age $\geq 45$} \\
Nids & No kids & Kids & No kids \\
No FT education & 33.2 & 45.9 & 35.9 & 54.7 \\
ALS $<16$ & 27.5 & 40.2 & 39.8 & 58.5 \\
ALS 16-19 & 43.4 & 47.1 & 50.9 & 64.1 \\
ALS 20+ & 59.3 & 63.5 & 69.1 & 81.5 \\
Still studying & 59.4 & 59.7 & 51.4 & 57.4 \\
All & 50.0 & 55.0 & 54.0 & 67.3
\end{tabular}

For those under the age of 45, the percentage who never have difficulty in paying bills is twelve percentage points lower with children present for those with the lowest level of education of no full-time education, but the analogous gap is only a third of this figure (at four percentage points) for those with higher levels of education. The differences for those aged 45 or more are even more striking: the percentage who never have difficulty in paying bills is nearly twenty percentage points lower with children present for those with the two lowest levels of education, with analogous figures for medium (ALS 16-19) and higher education (ALS 20+) of 14 and 12 percentage points respectively.

To see whether financial difficulties attenuate the effect of children on life satisfaction, we explicitly introduce them into the life-satisfaction equation in Table 6. The estimated coefficients on the difficulty paying bills dummies are extremely significant and negative with t-values of over 100 and are correlated with life satisfaction in the way that we would expect. They are larger in size for the older age group. 
The most interesting aspect of Table 6 is that, overall, for both men and women and for both age groups, and then separately for men and women under the age of forty-five, the coefficient on the children present variable now becomes significantly positive in all five cases. When we ran the equation for men only the child variable was insignificant whereas for women it was significant and positive. If we restrict the sample by age and then re-estimated it separately by gender, in both cases the children coefficient is insignificantly different from zero (results not reported).

Controlling for financial difficulties we then find that children now increase happiness. Why else would you have them? This appears to solve the puzzle in the literature. It seems crucial to control for the household's financial circumstances, and once we do so the sign on the child-present variable switches sign. We now carry out a number of further tests to show that result is very stable to changes in specification.

Table 7 splits the sample into sixteen richer and nineteen poorer countries, as defined by GDP per capita. The poor grouping consists of fifteen former Communist countries in Eastern Europe (Albania; Bulgaria; Croatia; Czech Republic; Estonia; Hungary; Latvia; Lithuania; Makedonia; Montenegro; Poland; Romania; Serbia; Slovakia and Slovenia) plus four poorer Western countries (Cyprus, Greece, Turkey and Turkish Cyprus). The richer countries are Austria; Belgium; Denmark; Finland; France; Germany; Iceland; Ireland; Italy; Luxembourg; Malta; Netherlands; Portugal; Spain; Sweden and the UK. We find that in both richer and poorer countries, without controlling for the difficulty in paying bills, children reduce happiness, with the coefficient on the child variable being significant and negative. In both groups of countries, once the financial difficulties that children presumably help bring are controlled for in columns 2 and 4 the sign switches to being significantly positive. Hence children bring happiness in both rich and poor countries once the financial difficulties they likely induce are controlled for. Children are expensive. One of our daughters, who has three kids under three, goes through eight gallons of milk a week.

In Table 8 we replace the children-present $(1,0)$ dummy with two variables for the number of children in the household under the age of ten and the number aged 10-14. The results are reported separately by age group, with the same controls as in the previous tables. The number of young children always enters significantly positively in both specifications for the younger age group, independently of controlling for difficulty in paying bills. Teenagers are associated with happiness in the younger sample only when financial difficulties are controlled for in the second column. Children of all ages attract negative significant estimated coefficients for the older age group in column 3 without financial controls. When these are introduced in column 4 , both children variables attract positive coefficients, although that for teenagers is only weakly significant $(\mathrm{t}=1.79)$.

Table 9 reports three sets of results derived from three separate equations for each of our thirtyfive European countries, and overall. The sample size refers to the estimates from columns 1 and 2. The first column reports the sign on the children variable using the same specification as in column 1 of Table 3. The second column adds the two difficulty of paying bills variables. The final two columns are obtained from the same equation, which includes the difficulty of paying bills variables but replaces the child present variable with the numbers of children under 10 and 
10-14. The symbols are as follows: + if the coefficient is positive and significant $(t \geq 1.96)$, - if it is negative and significant $(\mathrm{t} \geq 1.96)$ and $*$ if it is statistically insignificantly different from zero $(\mathrm{t}<1.96)$.

In column 1, out of the thirty-six lines there are sixteen significant negatives and six significant positives and fourteen that are insignificant. Column 2 then reports the same coefficient when the two financial variables are added. There are now only three significant negative children coefficients for Malta, Holland and Spain, but thirteen significant positives. In column 3 there are twenty-seven positives and only one significant negative, for Malta. In column 4 there are six positives and only one negative for Hungary. It does then seem that younger children make their parents happy, but teenagers rather less so.

Last, Table 10 reverts to the broader marital-status and children classifications of Table 4, but now including the two paying-bills variables. These two latter are again very significantly negative; financial burdens lower well-being. In column 1 the married with children from the present relationship are the happiest, while the married with children from a previous marriage are less happy than married people with no kids. Singles, divorced, separated and widowed with or without children are all unhappy.

For the younger age group in column two the married with children from that marriage are the happiest; whether there are kids as well from a previous marriage makes no significant difference. For the older age group there is no significant difference between those married without kids and those with children from that marriage. However, if they only have kids from a previous marriage, they are less happy than any other married group.

Controlling for financial variables matters. Comparing the results in Table 10 to those (without financial difficulties) in Table 4, we can see that the financial implications of children explain the lion's share of the negative children coefficient for those who are married or cohabiting. For the single, divorced/separated and widowed, the children coefficient is also smaller when controlling for financial difficulties, but only of the order of one quarter to one half.

Even controlling for financial difficulties, marital status continues to matter. The married and those cohabiting are happier with children (from this marriage/partnership) than without children. The presence of children for the divorced, separated or widowed does not convey additional happiness compared to others with the same marital status who have no kids. The single, divorced, separated or widowed, whether they have children or not, continue to be less happy than the married or cohabiting, whether or not the latter have children from this or a previous relationship. Married people with kids from that relationship are happiest when under 45; for those over 45 the married people are also the happiest but here the presence of children the current marriage does not add to happiness.

\section{Conclusion}

We have here investigated the relationship between children and parental subjective well-being. In our baseline specifications using information on over one million Europeans we find the same result as in the existing literature: children do not raise life satisfaction. Our contribution here is 
to explain this perhaps counter-intuitive result by the correlation between children and financial hardship.

We have information on the difficulty individuals have in paying their bills. When we control for this variable in life-satisfaction regressions, the negative as well as the insignificant estimated coefficients on children disappear in the vast majority of cases. Children then raise happiness as long as they do not lead to difficulties in paying the bills. According to our estimation results, a couple that has children and continues to have no problems in paying the bills will become happier by doing so: equally, a couple that sometimes had difficulty paying bills before children and continues to sometimes have difficulty after children will also be happier from having children. The negative effect of children the comes from their effect on financial difficulties. We argue that the existing results in the literature on the groups whose well-being is more likely to be positively correlated with children (those in richer countries, those with higher income, older parents) can all be read in this light.

Even so, not all children are equally correlated with parental life satisfaction. We first find that child age matters. In particular, younger children (those aged up to ten) appear to make parents happier, but the presence of young teenagers less so. Second, the correlation between children and life satisfaction depends on whose children they are. In our baseline results, parents with children from a previous relationship systematically report lower life satisfaction than those with children from the current relationship, with a life satisfaction gap of around 0.1 of a point. It is notable that the largest part of this gap reflects again the correlations of (step-)children with family finances: once we control for difficulties in paying bills, the gap between own and others' children is sharply reduced in size, although it remains significant.

Marital status matters when determining whether children bring happiness. We could find little or no significant difference for either age group, for example, between those with or without children who are separated or divorced. the same applied to the single and to the widowed. Having children raises the happiness of married people compared to those who have no kids. The married and those who live together, whether or not they had children, are everywhere significantly happier than those in the other categories with or without children.

Our broad conclusions are then two-fold. First, that children are associated with greater parental satisfaction in favourable financial circumstances. Second, that not all children are the same. In particular, economic downturns, by increasing financial distress, will diminish the satisfaction return from children. In addition, the answer to the question "Yours or Mine?" is important, with step-children being systematically associated with lower life satisfaction than own children, a relationship that is also partly mediated by financial distress. This distinction will arguably become increasingly important in European countries with the shorter duration of relationships and the rise in second marriages. 


\section{References}

Aassve, A., Goisis, A. and M. Sironi (2012). "Happiness and Childbearing Across Europe". Social Indicators Research, 108, pp. 65-86.

Alesina, A., Di Tella R., and R. MacCulloch (2004). "Inequality and Happiness: Are Europeans and Americans Different?". Journal of Public Economics, 88, pp. 2009-2042.

Blanchflower, D.G. (2019). Not Working: Who Gets the Good Jobs? Princeton NJ: Princeton University Press.

Blanchflower, D.G. and A.J. Oswald (2004). "Well-Being over Time in Britain and the USA". Journal of Public Economics, 88, pp. 1359-1386.

Blanchflower, D.G. and A.J. Oswald (2008). "Is Well-being U-shaped over the Life Cycle?". Social Science and Medicine, 66, pp. 1733-1749.

Blanchflower, D.G. and A.J. Oswald (2018). "Do modern humans suffer a psychological low in midlife? Two approaches (with and without controls) in seven data sets". Forthcoming in volume in honor of Dick Easterlin.

Cetre, S., Clark, A.E., and C. Senik (2016). "Happy People Have Children: Choice and SelfSelection into Parenthood". European Journal of Population, 32, pp. 445-473.

Clark, A.E., D'Ambrosio, C., and M. Barazzetta (2017). "Childhood Circumstances and Young Adulthood Outcomes: The Effects of Mothers' Financial Problems”. PSE Working Paper No. 2017-44.

Clark, A.E., Diener, E., Georgellis, Y., and R. Lucas (2008). "Lags and Leads in Life Satisfaction: A Test of the Baseline Hypothesis". Economic Journal, 118, pp. F222-F243.

Clark, A.E., Flèche, S., Layard, R., Powdthavee, N., and G. Ward (2018). The Origins of Happiness: The Science of Well-Being over the Life-Course. Princeton NJ: Princeton University Press.

Clark, A.E., and Y. Georgellis (2013). "Back to Baseline in Britain: Adaptation in the BHPS". Economica, 80, pp. 496-512.

Clark, A.E., Oswald, A.J., and P.B. Warr (1996). “Is Job Satisfaction U-shaped in Age?”. Journal of Occupational and Organizational Psychology, 69, pp. 57-81.

Costa-Font, J., Flèche, S., and R. Pagan (2018). "Parental Leave, Fertility and Well-being". LSE, mimeo.

Deaton, A., and A. Stone (2014). "Evaluative and hedonic wellbeing among those with and without children at home". Proceedings of the National Academy of Sciences 111, pp. 1328-1333. 
Glass, J., R. W. Simon, and M.A. Andersson (2016). "Parenthood and happiness: Effects of workfamily reconciliation policies in 22 OECD countries". American Journal of Sociology, 122 (3), p. 886-929

Herbst, C. M. and J. Ifcher (2016). "The Increasing Happiness of U.S. Parents". Review of Economics of the Household, 14(3), 529-551.

Kahneman D, A.B. Krueger, D.A. Schkade, N. Schwarz and A.A. Stone (2004). "A survey method for characterizing daily life experience: the day reconstruction method". Science. Dec 3; 306(5702), pp.1776-80.

Margolis, R., and M. Myrskylä (2011). "A Global Perspective on Happiness and Fertility". Population and Development Review, 37, pp. 29-56.

Myrskyla, M., and R. Margolis (2014). "Happiness: Before and After the Kids". Demography, 51, pp. 1843-1866.

Stanca, L. (2012). "Suffer the little children: Measuring the effects of parenthood on well-being worldwide". Journal of Economic Behavior and Organization, 81, pp. 742-750.

Stutzer, A., and B.S. Frey (2006). "Does Marriage Make People Happy, Or Do Happy People Get Married?”. Journal of Socio-Economics, 35, pp. 326-347. 
Table 1. Life satisfaction by country, 2009, 2015 and 2018

\begin{tabular}{|c|c|c|c|c|}
\hline & 2009 & 2015 & 2018 & 2018-2009 \\
\hline All & 2.86 & 2.99 & 3.01 & 0.15 \\
\hline Austria & 2.97 & 3.17 & 3.27 & 0.30 \\
\hline Belgium & 3.17 & 3.20 & 3.10 & -0.07 \\
\hline Bulgaria & 2.21 & 2.36 & 2.47 & 0.26 \\
\hline Croatia & 2.82 & 2.89 & 2.81 & -0.01 \\
\hline Cyprus & 3.15 & 3.07 & 3.12 & -0.03 \\
\hline Denmark & 3.67 & 3.71 & 3.71 & 0.04 \\
\hline Estonia & 2.75 & 2.86 & 2.92 & 0.17 \\
\hline Finland & 3.29 & 3.34 & 3.30 & 0.01 \\
\hline France & 2.93 & 3.04 & 3.01 & 0.08 \\
\hline Germany & 2.90 & 3.16 & 3.17 & 0.27 \\
\hline Greece & 2.35 & 2.32 & 2.38 & 0.03 \\
\hline Hungary & 2.30 & 2.66 & 2.75 & 0.45 \\
\hline Ireland & 3.27 & 3.34 & 3.41 & 0.14 \\
\hline Italy & 2.64 & 2.69 & 2.71 & 0.07 \\
\hline Latvia & 2.43 & 2.83 & 2.83 & 0.40 \\
\hline Lithuania & 2.51 & 2.83 & 2.80 & 0.29 \\
\hline Luxembourg & 3.36 & 3.37 & 3.35 & -0.01 \\
\hline Macedonia & 2.55 & 2.54 & 2.57 & 0.02 \\
\hline Malta & 3.05 & 3.28 & 3.22 & 0.17 \\
\hline Netherlands & 3.46 & 3.49 & 3.49 & 0.03 \\
\hline Poland & 2.82 & 2.97 & 3.05 & 0.23 \\
\hline Portugal & 2.35 & 2.55 & 2.74 & 0.39 \\
\hline Romania & 2.41 & 2.63 & 2.66 & 0.25 \\
\hline Slovakia & 2.73 & 2.80 & 2.86 & 0.13 \\
\hline Slovenia & 3.04 & 3.10 & 3.16 & 0.12 \\
\hline Spain & 2.88 & 2.97 & 3.05 & 0.17 \\
\hline Sweden & 3.46 & 3.48 & 3.45 & -0.01 \\
\hline Turkey & 2.61 & 2.67 & 2.96 & 0.35 \\
\hline Turkish Cyprus & 2.60 & 2.50 & 2.76 & 0.16 \\
\hline UK & 3.25 & 3.40 & 3.38 & 0.13 \\
\hline
\end{tabular}


Table 2. Marital Status, Children and Life Satisfaction across Europe

All

1. (Re-) Married living without children 3.00

2. (Re-) Married living with children of this marriage 2.92

3. (Re-) Married living with children of a previous marriage 2.97

4. (Re-) Married living with children of this marriage and a previous marriage $\quad 2.96$

5. Single living with partner without children $\quad 3.02$

6. Single living with partner with children of this partnership 3.01

7. Single living with partner with children of a previous marriage/partnership 3.01

8. Single living with partner with children of this and previous marriage/partnership 2.99

9. Single living without children $\quad 2.82$

10. Single living with children $\quad 2.97$

11. Divorced or separated living without children $\quad 2.77$

12. Divorced or separated living with children $\quad 2.70$

13. Widow/er living without children $\quad 2.79$

14. Widow/er living with children $\quad 2.60$

15. Missing/Other 3.06

Single $\quad 2.97$

Living together $\quad 3.00$

Married 2.96

Divorced/separated $\quad 2.75$

Widowed 2.76

Other $\quad 3.05$

With children $\quad 2.92$

Without children $\quad 2.95$

Children age $<10$

$0 \quad 2.92$

$1-2.94$

$2-3.03$

$3-3.06$

$4 \quad 2.91$

$\geq 5 \quad 2.89$

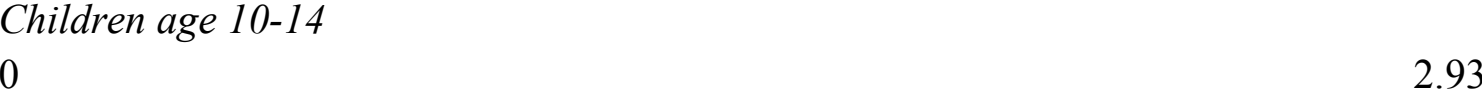

$1 \quad 2.93$

22.96

$3 \quad 2.89$

$4 \quad 2.74$

$\geq 5 \quad 2.88$

Notes: Eurobarometer data 2009-2018. 
Table 3. Life satisfaction, narrow marital status and presence of children, 2009-2018.

$\begin{array}{lccccc} & \text { All } & \text { Age }<45 & \text { Age } \geq 45 & \text { Male } & \text { Female } \\ \text { Children present } & -.0276(17.02) & -.0118(4.32) & -.0187(8.55) & -.0249(9.93) & -.0342(15.13) \\ \text { Living together } & -.0744(31.91) & -.0703(22.04) & -.1019(26.78) & -.0638(18.78) & -.0796(24.76) \\ \text { Single } & -.1414(63.17) & -.1211(37.02) & -.1943(56.80) & -.1244(37.78) & -.1501(48.46) \\ \text { Divorced/separated } & -.2564(95.50) & -.2791(53.96) & -.2400(76.36) & -.2592(59.34) & -.2511(73.41) \\ \text { Widowed } & -.1899(71.70) & -.1792(18.98) & -.18851(65.88) & -.2043(40.12) & -.1769(55.15) \\ \text { Marital refuse/DK } & -.0658(10.24) & -.0498(6.63) & -.1226(8.85) & -.0472(5.31) & -.0771(8.28) \\ \text { Age } & -.0136(68.48) & .0001(0.09) & .0031(3.76) & -.0145(49.18) & -.0127(47.26) \\ \text { Age }{ }^{2 * 100} & .0132(65.04) & -.0110(9.85) & .0011(1.81) & .0144(47.28) & .0121(44.52) \\ \text { Male } & -.0301(21.38) & -.0315(6.63) & -.0321(17.11) & & \\ & & & & & 3.1671 \\ \text { Constant } & 3.2137 & 2.9957 & 2.6827 & .2370 & .2675 \\ \text { Adjusted R } \mathrm{R}^{2} & .2631 & .2276 & .2948 & 498,706 & 565,466\end{array}$

Notes: All equations include 34 country dummies, 5 schooling dummies, 9 year-dummies and 4 labor-force status dummies. Excluded category is married. T-statistics appear in parentheses 
Table 4. Life satisfaction, broad marital status and children, 2009-2018.

\begin{tabular}{lccc} 
& \multicolumn{1}{c}{ All } & Age & Age $\geq 45$ \\
(Re-) Married living with children of this marriage & $-.0131(6.40)$ & $.0167(4.28)$ & $-.0115(4.37)$ \\
(Re-) Married living with children of a previous marriage & $-.0860(10.89)$ & $-.0574(5.35)$ & $-.0875(7.36)$ \\
(Re-) Married living with children of this marriage \& previous marriage & $-.0718(9.64)$ & $-.0407(4.44)$ & $-.0911(6.58)$ \\
Single living with partner without children & $-.0726(23.62)$ & $-.0563(11.98)$ & $-.0980(20.23)$ \\
Single living with partner with children of this partnership & $-.0754(18.12)$ & $-.0459(8.19)$ & $-.1097(14.04)$ \\
Single living with partner with children of a previous marriage & $-.1170(13.33)$ & $-.0926(8.02)$ & $-.1119(8.09)$ \\
Single living with partner with children of this and previous marriage & $-.1357(14.72)$ & $-.0802(5.18)$ & $-.1666(14.21)$ \\
Single living without children & $-.1267(50.59)$ & $-.0932(22.32)$ & $-.1886(51.57)$ \\
Single living with children & $-.2330(42.73)$ & $-.1866(26.44)$ & $-.2489(25.40)$ \\
Divorced or separated living without children & $-.2482(75.01)$ & $-.2596(31.87)$ & $-.2386(65.75)$ \\
Divorced or separated living with children & $-.2846(61.36)$ & $-.2724(37.02)$ & $-.2570(41.70)$ \\
Widow/er living without children & $-.1847(63.15)$ & $-.1395(11.88)$ & $-.1844(60.05)$ \\
Widow/er living with children & $-.2217(40.63)$ & $-.2236(14.31)$ & $-.2021(34.60)$ \\
Other & $-.0551(8.18)$ & $-.0270(3.36)$ & $-.1233(8.05)$ \\
Refused & $-.0962(4.45)$ & $-.0728(2.50)$ & $-.1110(3.47)$ \\
Age & $-.0136(68.44)$ & $-.0000(0.03)$ & $.0032(3.88)$ \\
Age squared $* 100$ & & $-.0109(9.83)$ & $.0011(1.70)$ \\
Male & & $-.0339(15.88)$ & $-.0326(17.40)$ \\
Constant & $-.0317(22.49)$ & & \\
Adjusted R & & & 2.6842 \\
N & & & .2950
\end{tabular}

Notes: The excluded categories are married without children and France. All equations include 34 country dummies, 6 schooling dummies, 9 year-dummies and 4 labor-force status dummies. T-statistics appear in parentheses. 
Table 5. Difficulty Paying Bills, 2009-2018 (N=1,002,877)

All

(Re-) Married living without children

(Re-) Married living with children of this marriage

(Re-) Married living with children of a previous marriage

(Re-) Married living with children of this marriage and a previous marriage

Single living with partner without children

Single living with partner with children of this partnership

Single living with partner with children of a previous marriage/partnership

Single living with partner with children of this and a previous marriage/partnership

Single living without children

Single living with children

Divorced or separated living without children

Divorced or separated living with children

Widow/er living without children

Widow/er living with children

Never From time to time All the time

With children

Without children

Children age $<10$

1

2

3

$\geq 5$

Children age 10-14

1

2

$\begin{array}{rrr}59 & 29 & 12 \\ 69 & 23 & 8 \\ 53 & 33 & 14 \\ 52 & 33 & 15 \\ 53 & 32 & 16 \\ 59 & 30 & 11 \\ 54 & 32 & 14 \\ 53 & 32 & 15 \\ 49 & 33 & 19 \\ 57 & 31 & 12 \\ 44 & 35 & 22 \\ 57 & 28 & 16 \\ 41 & 36 & 23 \\ 64 & 24 & 12 \\ 50 & 31 & 19 \\ & & \\ 52 & 33 & 15 \\ 63 & 26 & 11 \\ 61 & 28 & 12 \\ 61 & 28 & 12 \\ 50 & 35 & 15 \\ 52 & 33 & 15 \\ 47 & 34 & 20 \\ 38 & 34 & 28 \\ 40 & 32 & 27 \\ 60 & 28 & 12 \\ 50 & 34 & 16 \\ 60 & 28 & 12 \\ 50 & 34 & 15 \\ 50 & 33 & 17 \\ 40 & 35 & 25 \\ 45 & 42 & 13\end{array}$


Table 6. Life satisfaction, difficulty in paying bills, marital status and children, 2009-2018

\begin{tabular}{|c|c|c|c|c|c|}
\hline & All & Age $<45$ & Age $\geq 45$ & Males age $<45$ & Females age $<45$ \\
\hline Children present & $.0055(3.37)$ & $.0199(7.18)$ & $.0042(1.92)$ & $.0233(5.40)$ & $.0125(3.38)$ \\
\hline From time to time difficulty paying bills & $-.2790(172.14)$ & $-.2517(106.44)$ & $-.2999(135.09)$ & $-.2603(73.78)$ & $-.2367(76.52)$ \\
\hline Most of the time difficulty paying bills & $-.6359(278.57)$ & $-.5717(169.33)$ & $-.6771(218.57)$ & $-.5810(112.73)$ & $-.5606(125.36)$ \\
\hline Living together & $-.0339(14.46)$ & $-.0384(12.12)$ & $-.0588(15.00)$ & $-.0279(5.82)$ & $-.0462(10.91)$ \\
\hline Single & $-.1041(47.72)$ & $-.0925(28.52)$ & $-.1477(44.56)$ & $-.0762(15.31)$ & $-.1061(24.36)$ \\
\hline Divorced/separated & $-.1871(71.79)$ & $-.2064(40.92)$ & $-.1707(56.07)$ & $-.2023(23.09)$ & $-.2094(33.77)$ \\
\hline Widowed & $-.1563(60.89)$ & $-.1605(17.50)$ & $-.1488(54.78)$ & $-.1268(7.15)$ & $-.1720(15.81)$ \\
\hline Married DK & $-.0516(7.97)$ & $-.0441(5.79)$ & $-.0972(7.04)$ & $-.0266(2.51)$ & $-.0588(5.32)$ \\
\hline Age & $-.0114(58.73)$ & $.0040(6.36)$ & $-.0022(2.70)$ & $.0024(2.56)$ & $.0052(6.06)$ \\
\hline $\operatorname{Age}^{2 *} 100$ & $.0102(51.42)$ & $-.0171(15.70)$ & $.0036(5.93)$ & $-.0151(9.21)$ & $-.0184(12.52)$ \\
\hline Male & $-.0363(25.67)$ & $-.0384(18.20)$ & -.0365 (19.98) & & \\
\hline Constant & 3.3961 & 3.1800 & 3.1055 & 3.1882 & 3.1456 \\
\hline Adjusted $\mathrm{R}^{2}$ & .3217 & .2817 & .3546 & .2826 & .2819 \\
\hline $\mathrm{N}$ & 997,700 & 422,065 & 575,635 & 195,432 & 226,633 \\
\hline
\end{tabular}

Notes: All equations include 34 country dummies, 5 schooling dummies, 9 year-dummies and 4 labor-force status dummies. The excluded categories are married and never has difficulty paying bills. T-statistics appear in parentheses. The analysis excludes survey \#71.1, which does not have the pay bills question coded in this way. 
Table 7. Life satisfaction, difficulty in paying bills, marital status and children in rich and poor countries, 2009-2018

Children present

From time to time difficulty paying bills

Most of the time difficulty paying bills

Living together

Single

Divorced/separated

Widowed

Married DK

Age

$\mathrm{Age}^{2 *} 100$

Male

Constant

Adjusted R ${ }^{2}$

$\mathrm{N}$

\begin{tabular}{ll}
\multicolumn{2}{c}{ Richer countries } \\
$-.0299(14.06)$ & $.0058(13.34)$ \\
& $-.2790(123.99)$ \\
& $-.6094(177.81)$ \\
$-.0833(28.62)$ & $-.0413(14.07)$ \\
$-.1831(66.34)$ & $-.1405(51.50)$ \\
$-.2648(78.37)$ & $-.1984(60.10)$ \\
$-.1972(55.54)$ & $-.1723(49.82)$ \\
$-.0855(9.25)$ & $-.0707(7.49)$ \\
$-.0101(39.63)$ & $-.0086(34.32)$ \\
$.0108(41.78)$ & $.0084(33.06)$ \\
$-.0327(18.00)$ & $-.0394(21.96)$ \\
& \\
3.1416 & 3.3346 \\
.2351 & .2891 \\
531,063 & 507,234
\end{tabular}

Poorer countries

$\begin{array}{ll}-.0114(4.63) & .0161(6.63) \\ & -.2744(117.75) \\ & -.6395(175.19) \\ -.0615(16.60) & -.0253(6.75) \\ -.0836(23.09) & -.0560(15.74) \\ -.2493(59.03) & -.1784(43.65) \\ -.1641(41.79) & -.1263(33.30) \\ -.0376(4.19) & -.0287(3.19) \\ -.0158(51.21) & -.0132(44.05) \\ .0141(44.29) & .0109(35.18) \\ -.0310(14.4) & -.0358(16.99) \\ & \\ 2.8224 & .1560 \\ .1657 & .2923 \\ 513,109 & 490,466\end{array}$

Notes: Both sets of equations include the appropriate country dummies, 5 schooling dummies, 9 year-dummies and 4 labor-force status dummies. The excluded categories are married and never has difficulty paying bills. T-statistics appear in parentheses. The analysis excludes survey \#71.1, which does not have the pay bills question coded in this way. The poorer countries are the former Soviet-bloc countries (Albania; Bulgaria; Croatia; Czech Republic; Estonia; Hungary; Latvia; Lithuania; Macedonia; Montenegro; Poland; Romania; Serbia; Slovakia and Slovenia) plus Greece, Cyprus, Turkey and Turkish Cyprus. 
Table 8. Life satisfaction, difficulty in paying bills, marital status and numbers of children ages $<10$ and $10-14,2009-2018$

\begin{tabular}{|c|c|c|c|c|}
\hline \multirow[b]{2}{*}{ Number children $<10$ years of age } & \multicolumn{2}{|c|}{ Age $<45$} & \multicolumn{2}{|c|}{ Age $\geq 45$} \\
\hline & $.0149(11.12)$ & $.0268(20.13)$ & $-.0050(2.15)$ & $.0116(5.15)$ \\
\hline Number children $10-14$ years of age & $-.0010(0.57)$ & $.0105(5.78)$ & $-.0087(3.79)$ & $.0041(1.79)$ \\
\hline From time to time difficulty paying bills & & $-.2527(106.90)$ & & $-.3001(135.18)$ \\
\hline All the time difficulty paying bills & & $-.5745(10.16)$ & & $-.6777(218.669)$ \\
\hline Living together & $-.0594(19.17)$ & $-.0317(10.31)$ & $-.1017(26.72)$ & $-.0592(15.13)$ \\
\hline Single & $-.1037(34.41)$ & $-.0830(27.73)$ & $-.1901(56.36)$ & $-.1477(45.29)$ \\
\hline Divorced/separated & $-.2702(52.31)$ & $-.1987(39.48)$ & $-.2381(76.02)$ & $-.1706(56.26)$ \\
\hline Widowed & $-.1709(18.12)$ & $-.1543(16.85)$ & $-.1840(65.60)$ & $-.1488(54.84)$ \\
\hline Married DK & $-.0325(8.42)$ & $-.0377(5.07)$ & $-.1141(8.25)$ & $-.0982(7.12)$ \\
\hline Age & $-.0008(1.20)$ & $.0029(4.48)$ & $.0039(4.69)$ & $-.0019(2.32)$ \\
\hline $\operatorname{Age}^{2 *} 100$ & $-.0097(8.58)$ & $-.0150(13.52)$ & $.0006(1.06)$ & $.0034(5.55)$ \\
\hline Male & $-.0298(14.11)$ & $-.0387(18.47)$ & $-.0324(16.89)$ & $-.0369(20.17)$ \\
\hline Constant & 2.9867 & 3.1819 & 2.6484 & 3.0934 \\
\hline Adjusted $\mathrm{R}^{2}$ & .2279 & .2823 & .2948 & .3546 \\
\hline $\mathrm{N}$ & 445,342 & 422,028 & 598,736 & 575,582 \\
\hline
\end{tabular}

Notes: The quations include 34 country dummies, 5 schooling dummies, 9 year-dummies and 4 labor-force status dummies. The excluded categories are married and never has difficulty paying bills. T-statistics appear in parentheses. The analysis in columns 2 and 4 excludes survey \#71.1, which does not have the pay bills question coded in this way. 
Table 9. Life satisfaction and children by country, 2009-2018.

\begin{tabular}{|c|c|c|c|c|c|}
\hline & introls & With controls & $\#$ age $<10$ & \# ages 10-14 & $N$ \\
\hline All & - & + & + & + & 997,610 \\
\hline Albania & * & * & * & * & 7,164 \\
\hline Austria & + & + & + & * & 32,769 \\
\hline Belgium & - & * & + & $*$ & 34,220 \\
\hline Bulgaria & * & $*$ & * & * & 33,054 \\
\hline Croatia & * & + & + & + & 31,791 \\
\hline Cyprus & - & $*$ & + & * & 16,852 \\
\hline Czech Republic & * & + & + & * & 34,303 \\
\hline Denmark & - & * & * & * & 34,099 \\
\hline Estonia & + & + & + & + & 33,625 \\
\hline Finland & + & + & + & * & 34,007 \\
\hline France & - & + & + & $*$ & 34,061 \\
\hline Germany & + & + & + & + & 51,076 \\
\hline Greece & - & $*$ & $*$ & $*$ & 33,987 \\
\hline Hungary & * & * & + & - & 34,493 \\
\hline Iceland & * & + & + & $*$ & 5,458 \\
\hline Ireland & - & + & + & * & 33,487 \\
\hline Italy & + & + & + & * & 32,970 \\
\hline Latvia & $*$ & + & + & * & 33,755 \\
\hline Lithuania & * & * & + & * & 34,051 \\
\hline Luxembourg & - & * & $*$ & * & 16,839 \\
\hline Macedonia & - & * & + & + & 16,605 \\
\hline Malta & - & - & - & * & 16,872 \\
\hline Montenegro & * & $*$ & $*$ & $*$ & 8,387 \\
\hline Netherlands & - & - & + & $*$ & 34,381 \\
\hline Poland & * & $*$ & + & $*$ & 32,170 \\
\hline Portugal & $*$ & $*$ & + & $*$ & 34,459 \\
\hline Romania & * & * & + & $*$ & 34,228 \\
\hline Serbia & + & + & * & * & 10,592 \\
\hline Slovakia & $*$ & * & + & * & 33,660 \\
\hline Slovenia & * & * & + & * & 34,290 \\
\hline Spain & - & - & + & * & 34,011 \\
\hline Sweden & - & * & + & * & 34,801 \\
\hline Turkey & - & * & $*$ & * & 16,772 \\
\hline Turkish Cyprus & - & * & + & + & 10,693 \\
\hline United Kingdom & - & $*$ & + & * & 43,724 \\
\hline
\end{tabular}

Notes: Columns 1 and 2 indicate whether the coefficient on the presence of children is significantly positive $(+)$, significantly negative $(-)$ or insignificant $(*)$. The second column contains two paying bills controls. The third and fourth columns replace the children present variable with \# children by age and include the paying bills variables. The sample excludes Eurobarometer \#71.1. The other controls are as listed in Table 3. Sample sizes are for columns 1 and 2. 


\section{Table 10. Life satisfaction, difficulty in paying bills, broad marital status and children, 2009-2018}

From time to time difficulty in paying bills

All the time difficulty in paying bills

(Re-) Married living with children of this marriage

(Re-) Married living with children of a previous marriage

(Re-) Married living with children of this \& prior marriage

Single living with partner without children

Single living with partner with children of this partnership

Single living with partner with children of a previous marriage

Single living with partner with children this \& prior marriage

Single living without children

Single living with children

Divorced or separated living without children

Divorced or separated living with children

Widow/er living without children

Widow/er living with children

Other

Refused

Age

Age $^{2}$

Male

Constant

Adjusted $\mathrm{R}^{2}$

$\mathrm{N}$

Notes: All equations include 34 country dummies, 5 schooling dummies, 997,700
All

$-.2787(171.94)$

$-.6352(278.08)$

$.0090(4.47)$

$-.0243(2.73)$

$.0088(0.90)$

$-.0395(13.11)$

$-.0099(2.38)$

$-.0354(4.05)$

$-.0042(0.33)$

$-.0986(40.10)$

$-.1278(24.03)$

$-.1861(57.94)$

$-.1795(39.88)$

$-.1509(53.21)$

$-.1700(32.25)$

$-.0458(6.78)$

$-.0954(4.06)$

-.0113 (58.39)

$.0102(51.17)$

$-.0369(26.63)$
Age $<45$

$-.2511(106.14)$

$-.5703(168.75)$

$.0320(8.04)$

$.0092(0.70)$

.0363 (2.79)

$-.0322(6.83)$

$.0000(0.01)$

$-.0248(2.16)$

$-.0014(0.09)$

$-.0780(18.56)$

$-.1030(14.73)$

$-.2011(25.13)$

-.1747 (24.09)

$-.1323(11.57)$

-.1718 (11.31)

$-.0322(3.96)$

$-.0553(1.73)$

.0039 (6.28)

$-.0171(15.61)$

$-.0397(18.71)$
Age $\geq 45$

$-.2998(135.04)$

$-.6770(218.45)$

$.0037(1.47)$

$-.0383(3.12)$

$-.0125(0.82)$

$-.0666(14.15)$

$-.0422(5.14)$

$-.0374(2.66)$

$-.0064(0.25)$

$-.1477(41.71)$

$-.1500(15.78)$

-.1735 (49.43)

$-.1600(26.89)$

$-.1479(49.81)$

$-.1519(27.01)$

$-.0893(5.94)$

$-.1430(4.15)$

$-.0021(2.60)$

.0035 (5.79)

$-.0364(19.91)$

3.1035

.3546
3.1724

.2818 422,065
575,635

excluded categories are France and married without children. T-statistics appear in parentheses. The analysis excludes survey \#71.1, which does not have the pay bills question coded in this way. 
Appendix Table 1. Life satisfaction by year.

\begin{tabular}{|c|c|c|c|c|c|c|c|c|c|c|}
\hline & 2009 & 2010 & 2011 & 2012 & 2013 & 2014 & 2015 & 2016 & 2017 & 2018 \\
\hline All & 2.86 & 2.88 & 2.89 & 2.84 & 2.87 & 2.92 & 2.99 & 2.97 & 3.00 & 3.01 \\
\hline Albania & & & & & & 2.61 & 2.67 & 2.67 & 2.66 & 2.69 \\
\hline Austria & 2.97 & 3.05 & 3.05 & 3.06 & 3.06 & 3.17 & 3.17 & 3.17 & 3.25 & 3.27 \\
\hline Belgium & 3.17 & 3.14 & 3.21 & 3.17 & 3.20 & 3.15 & 3.20 & 3.18 & 3.15 & 3.10 \\
\hline Bulgaria & 2.21 & 2.18 & 2.25 & 2.23 & 2.13 & 2.25 & 2.36 & 2.38 & 2.46 & 2.47 \\
\hline Croatia & 2.82 & 2.80 & 2.73 & 2.72 & 2.81 & 2.81 & 2.89 & 2.85 & 2.84 & 2.81 \\
\hline Cyprus & 3.15 & 3.08 & 3.11 & 2.96 & 2.88 & 3.01 & 3.07 & 3.07 & 3.13 & 3.12 \\
\hline Denmark & 3.67 & 3.65 & 3.65 & 3.66 & 3.68 & 3.69 & 3.71 & 3.70 & 3.69 & 3.71 \\
\hline Estonia & 2.75 & 2.76 & 2.74 & 2.69 & 2.72 & 2.79 & 2.86 & 2.89 & 2.88 & 2.92 \\
\hline Finland & 3.29 & 3.27 & 3.30 & 3.24 & 3.28 & 3.28 & 3.34 & 3.33 & 3.32 & 3.30 \\
\hline France & 2.93 & 2.97 & 2.97 & 2.97 & 2.95 & 2.94 & 3.04 & 2.99 & 3.01 & 3.01 \\
\hline Germany & 2.90 & 3.01 & 3.08 & 3.09 & 3.12 & 3.13 & 3.16 & 3.14 & 3.18 & 3.17 \\
\hline Greece & 2.35 & 2.29 & 2.29 & 2.12 & 2.16 & 2.17 & 2.32 & 2.16 & 2.29 & 2.38 \\
\hline Hungary & 2.30 & 2.39 & 2.39 & 2.34 & 2.42 & 2.57 & 2.66 & 2.63 & 2.71 & 2.75 \\
\hline Iceland & & 3.59 & 3.54 & 3.57 & 3.55 & 3.54 & & & & \\
\hline Ireland & 3.27 & 3.17 & 3.25 & 3.10 & 3.11 & 3.27 & 3.34 & 3.39 & 3.38 & 3.41 \\
\hline Italy & 2.64 & 2.74 & 2.78 & 2.58 & 2.59 & 2.61 & 2.69 & 2.67 & 2.70 & 2.71 \\
\hline Latvia & 2.43 & 2.57 & 2.59 & 2.66 & 2.72 & 2.76 & 2.83 & 2.81 & 2.81 & 2.83 \\
\hline Lithuania & 2.51 & 2.48 & 2.56 & 2.62 & 2.72 & 2.75 & 2.83 & 2.72 & 2.76 & 2.80 \\
\hline Luxembourg & 3.36 & 3.36 & 3.39 & 3.33 & 3.31 & 3.33 & 3.37 & 3.35 & 3.32 & 3.35 \\
\hline Macedonia & 2.55 & 2.49 & 2.52 & 2.52 & 2.54 & 2.62 & 2.54 & 2.54 & 2.63 & 2.57 \\
\hline Malta & 3.05 & 2.93 & 3.04 & 2.90 & 3.17 & 3.26 & 3.28 & 3.20 & 3.22 & 3.22 \\
\hline Montenegro & & & 2.54 & 2.35 & 2.50 & 2.70 & 2.62 & 2.60 & 2.76 & 2.84 \\
\hline Netherlands & 3.46 & 3.44 & 3.48 & 3.45 & 3.42 & 3.45 & 3.49 & 3.49 & 3.48 & 3.49 \\
\hline Poland & 2.82 & 2.88 & 2.85 & 2.81 & 2.85 & 2.89 & 2.97 & 2.96 & 2.99 & 3.05 \\
\hline Portugal & 2.35 & 2.31 & 2.38 & 2.20 & 2.22 & 2.39 & 2.55 & 2.66 & 2.75 & 2.74 \\
\hline Romania & 2.41 & 2.19 & 2.33 & 2.34 & 2.34 & 2.49 & 2.63 & 2.64 & 2.65 & 2.66 \\
\hline Serbia & & & & 2.17 & 2.24 & 2.45 & 2.38 & 2.38 & 2.44 & 2.43 \\
\hline Slovakia & 2.73 & 2.85 & 2.80 & 2.72 & 2.69 & 2.75 & 2.80 & 2.87 & 2.88 & 2.86 \\
\hline Slovenia & 3.04 & 3.03 & 3.00 & 3.02 & 3.01 & 3.02 & 3.10 & 3.14 & 3.18 & 3.16 \\
\hline Spain & 2.88 & 2.87 & 2.87 & 2.76 & 2.84 & 2.87 & 2.97 & 2.97 & 3.03 & 3.05 \\
\hline Sweden & 3.46 & 3.42 & 3.47 & 3.46 & 3.46 & 3.44 & 3.48 & 3.45 & 3.44 & 3.45 \\
\hline Turkey & 2.61 & 2.72 & 2.67 & 2.64 & 2.73 & 2.78 & 2.67 & 2.75 & 2.86 & 2.96 \\
\hline Turkish Cyprus & 2.60 & 2.67 & 2.61 & 2.45 & 2.37 & 2.42 & 2.50 & 2.50 & 2.74 & 2.76 \\
\hline UK & 3.25 & 3.29 & 3.28 & 3.25 & 3.30 & 3.30 & 3.40 & 3.41 & 3.38 & 3.38 \\
\hline
\end{tabular}

